\title{
Uranium stripping from tri-n-butyl phosphate by hydrogen peroxide solutions
}

\author{
A.L. Smirnov ${ }^{\text {a }}$, S.Yu. Skripchenko ${ }^{\text {a,* }}$, V.N. Rychkov ${ }^{\text {a }}$, A.M. Pastukhov ${ }^{\text {a }}$, M.G. Shtutsa ${ }^{\text {b }}$ \\ a Department of Rare Metals and Nanomaterials, Institute of Physics and Technology, Ural Federal University, 620002, St. Mira, 19, Ekaterinburg, Russian Federation \\ b JSC Chepetsky Mechanical Plant, 427620, St. Belova, 7, Glazov, Udmurt Republic, Russian Federation
}

\section{A R T I C L E I N F O}

Article history:

Received 12 November 2012

Received in revised form 29 March 2013

Accepted 10 April 2013

Available online 22 April 2013

\section{Keywords:}

Solvent extraction

Uranium stripping

Tri-n-butyl phosphate

Hydrogen peroxide

Uranium peroxide

\begin{abstract}
A B S T R A C T
The processes of uranium stripping from 30\% tri- $n$-butyl phosphate (TBP) in "odorless" kerosene by $\mathrm{H}_{2} \mathrm{O}_{2}$ solutions both with and without $\mathrm{NH}_{4} \mathrm{OH}$ added were investigated in the temperature range of $20-50{ }^{\circ} \mathrm{C}$ and with a volumetric ratio of 1 between the organic and aqueous phases. The uranium was selectively precipitated in the form of uranium peroxide during stripping from the organic phase by hydrogen peroxide. The stripping of uranium increased with increasing $\mathrm{H}_{2} \mathrm{O}_{2}$ content, increasing temperature and increasing concentration of $\mathrm{NH}_{3}$ in the range of $0-15 \mathrm{~g} / \mathrm{L}$. The use of a heated solution $\left(40{ }^{\circ} \mathrm{C}\right)$ that contained $4 \mathrm{~mol}$ $\mathrm{H}_{2} \mathrm{O}_{2} / \mathrm{mol} \mathrm{U}$ and $\mathrm{NH}_{3} 12 \mathrm{~g} / \mathrm{L}$ resulted in $99.7 \%$ of the uranium being stripped from TBP in the form of uranium peroxide. The uranium peroxide obtained by stripping is a highly pure product that exists in two different hydrated forms: $\mathrm{UO}_{4} \cdot 4 \mathrm{H}_{2} \mathrm{O}\left(92\right.$ mass \%) and $\mathrm{UO}_{4} \cdot 2 \mathrm{H}_{2} \mathrm{O}$. The mean particle diameter was $20.75 \mu \mathrm{m}$. The effect of hydrogen peroxide on the organic phase was studied by IR spectroscopy. No structural changes in TBP were observed after 30 cycles of extraction/stripping; thus, the use of hydrogen peroxide in this application is unrestricted.
\end{abstract}

(c) 2013 Elsevier B.V. All rights reserved.

\section{Introduction}

Uranium concentrate obtained at a manufacturing plant in the form "yellow cake" or calcined yellow cake represents only the first step in the processing of uranium ore toward the production of enriched uranium (Hausen, 1998; Morss et al., 2010). Although the uranium has been separated from the majority of impurities present in the ore during the mining and milling operations, yellow cake is not a high-purity product and is normally further refined to produce nuclear-grade material (Morss et al., 2010; Wilson, 1996). Specifically, the uranium must be separated from elements with high thermal-neutron capture cross-sections and from other impurities that form volatile fluorides (Wilson, 1996). The uranium purification is performed either by solvent extraction from nitric acid solutions or by distillation of uranium hexafluoride (Edwards and Oliver, 2000; Morss et al., 2010). Solvent extraction is currently the most common method for uranium refining circuits. This process has been well described in the literature (Edwards and Oliver, 2000; Morss et al., 2010; Sato, 1958; Wilson, 1996). It consists of the dissolution of yellow cake in nitric acid and the selective extraction of uranium using tri-n-butyl phosphate (TBP). The purified uranium is usually stripped from the organic phase into the aqueous phase by water or diluted nitric acid. The product of uranium stripping (i.e., uranyl solution) is subsequently evaporated to a molten salt of uranyl nitrate. The molten uranyl nitrate is converted to $\mathrm{UO}_{3}$, reduced with hydrogen

\footnotetext{
* Corresponding author. Tel.: + 734337548 30; fax: + 73433745491 . E-mail address: uran233@mail.ru (S.Y. Skripchenko).
}

to $\mathrm{UO}_{2}$, and converted to $\mathrm{UF}_{4}$ with hydrogen fluoride at elevated temperatures (Morss et al., 2010).

This work describes the application of hydrogen peroxide as an alternative agent for the stripping of uranium from loaded TBP. This method differs from traditional methods that employ water (or diluted nitric acid) for stripping the metal from the organic phase. In fact, uranium is stripped from the loaded organic phase through direct precipitation in the form of uranium peroxide. The use of $\mathrm{H}_{2} \mathrm{O}_{2}$ for the precipitation of uranium as uranium peroxide has been mentioned in a number of publications. However, all of them describe a process of uranium precipitation from acidic solutions (e.g., mill solutions, in situ leach liquors, eluted solutions, and pregnant strip solutions) (Cahill and Burkhart, 1990; Caropreso and Kreuz, 1977; Gupta et al., 2004; Hardwick, 1984; Morais et al., 2005; Shabbir and Tame, 1974; Singh et al., 2002). This paper describes our research on the stripping of uranium from a loaded organic phase using hydrogen peroxide solutions. This process has several advantages (e.g., a product with greater purity, reduced volume of waste solutions, easy handling, etc.) and can lead to the elimination of some processing steps of uranium refining, such as the expensive operation of evaporation and unprofitable denitration stage.

\section{Experimental}

The loaded organic phase containing $78 \mathrm{~g} / \mathrm{L} \mathrm{U}(\mathrm{VI})$ and $15.34 \mathrm{~g} / \mathrm{L}$ $\mathrm{HNO}_{3}$ was prepared through the selective extraction of uranium from uranyl nitrate solution (120 g/L U(VI), $100 \mathrm{~g} / \mathrm{L} \mathrm{HNO}_{3}$ ) using 30\% 
(by volume) TBP in "odorless" kerosene. The extraction was conducted in a separatory funnel at room temperature $\left(20-25^{\circ} \mathrm{C}\right)$. The volumetric ratio between the organic and aqueous phases $(\mathrm{O} / \mathrm{A})$ was equal to 1 . The uranyl nitrate solution was prepared by the dissolution of ammonium polyuranate in nitric acid solution. Ammonium polyuranate was obtained from the ore uranium concentrate. The content of impurity elements in the uranyl nitrate solution was equal to $(\mathrm{mg} / \mathrm{L}): 228 \mathrm{Fe}, 204 \mathrm{~S}$, 7.6 K, 11.2 Na, 3 Mo, 0.46 V, 0.07 W, 192 Si, 72 P, 5.9 Cr, 0.192 B, 19.2 Cl, $40.8 \mathrm{Ti}, 94.8 \mathrm{Al}, 0.36 \mathrm{Cu}, 1.2 \mathrm{~Pb}, 3.36 \mathrm{Ni}, 6.24 \mathrm{Mn}, 0.216 \mathrm{Li}, 4.8 \mathrm{Mg}$, and 5.8 Ca. All other chemicals used were reagents of chemically pure grade.

The stripping procedures were performed in a separatory funnel $(100 \mathrm{~mL})$ at $20-50{ }^{\circ} \mathrm{C}$. In all the experiments, the volumetric ratio between the organic and aqueous phases $(\mathrm{O} / \mathrm{A})$ was equal to 1 . The uranium was stripped from the loaded organic phase by the addition of hydrogen peroxide, and the $\mathrm{pH}$ of the reaction was controlled through the addition of $5 \%$ ammonium hydroxide solution. The hydrogen peroxide solutions containing 1-30 mol $\mathrm{H}_{2} \mathrm{O}_{2}$ for each mol of uranium in the organic phase were prepared by the dilution of $30 \%$ hydrogen peroxide shortly prior to experiments. Distilled water was used in the dilutions.

The stripping experiments were performed using the following procedure. Equal volumes $(20 \mathrm{~mL})$ of loaded organic phase and hydrogen peroxide solution with or without $\mathrm{NH}_{4} \mathrm{OH}$ added were placed in a separatory funnel and were rapidly stirred. The phases were stirred $2 \mathrm{~min}$ in all of the experiments. The phases were allowed to stand alone prior to the precipitation of uranium peroxide $(0.15$ $24 \mathrm{~h}$ ). All three phases were subsequently separated.

The uranium concentration in the aqueous phase was determined using ICP-AES (Optima 2100 DV Perkin Elmer). The nitric acid content in the aqueous phase was determined by acid-base titration with methyl orange as an indicator. The analysis of uranium peroxide obtained by stripping was performed using ICP-AES. The uranium concentration and the $\mathrm{HNO}_{3}$ concentration in the organic phases were calculated on the basis of the mass balance.

$\mathrm{X}$-ray phase analysis of uranium peroxide powders was performed at STOE STADI-P. All infrared spectra of the organic phases and uranium compounds were measured in the range of $400-4000 \mathrm{~cm}^{-1}$ using a Bruker VERTEX 70 spectrometer. The measurements of IR spectra of uranium peroxide were performed on solid-phase samples using the $\mathrm{KBr}$ pellet technique. The mixtures of $\mathrm{KBr}$ and the samples were pressed into transparent pellets $(\mathrm{d}=13 \mathrm{~mm})$ at $600 \mathrm{MPa}$. IR spectra of the organic phases were obtained by placing one drop of a pure sample between polyethylene plates. The particle size distribution of uranium peroxide was determined using an Analysette 22 laser particle sizer. The thermogravimetric analysis (TGA) and differential thermal analysis (DTA) were performed on a Mettler Toledo TGA/SDTA 851e using a heating rate of $10{ }^{\circ} \mathrm{C} / \mathrm{min}$.

All the experiments were performed at least in duplicate, and the average error was less than $1.0 \%$.

\section{Results and discussion}

The use of a hydrogen peroxide solution for stripping from loaded organic phases results in the precipitation of uranium in the form of uranium peroxide, as shown in Eq. (1):

$\mathrm{UO}_{2}^{2+}+\mathrm{H}_{2} \mathrm{O}_{2}+\mathrm{nH}_{2} \mathrm{O}=\mathrm{UO}_{4} \cdot \mathrm{nH}_{2} \mathrm{O}+2 \mathrm{H}^{+}$

It is known that the use of excess of hydrogen peroxide, the $\mathrm{pH}$, the precipitation time and the temperature are importance known to be important in the production of uranium peroxide (Gupta et al., 2004; Kim et al., 2011). Therefore, in order to find optimal conditions for uranium stripping, the effects of the temperature, the concentrations of content of $\mathrm{H}_{2} \mathrm{O}_{2}$ and $\mathrm{NH}_{3}$ in the stripping solution, and the holding time of the phases were studied. The effect of the hydrogen peroxide on the organic phase was studied by IR spectroscopy.

\subsection{Effect of $\mathrm{H}_{2} \mathrm{O}_{2}$ content on the uranium stripping}

According to Eq. (1), one mol of $\mathrm{H}_{2} \mathrm{O}_{2}$ is required for each mol of uranium. However, the excess of hydrogen peroxide is known to be required for the precipitation of uranium from solutions (Cahill and Burkhart, 1990; Gupta et al., 2004; Morais et al., 2005). This necessary excess may vary according to the uranium solution composition (Morais et al., 2005).

The effect of the $\mathrm{H}_{2} \mathrm{O}_{2}$ content on the uranium stripping was studied at room temperature $\left(20-25{ }^{\circ} \mathrm{C}\right)$. The uranium was stripped from the loaded organic phase using hydrogen peroxide solutions (1-30 mol $\mathrm{H}_{2} \mathrm{O}_{2} / \mathrm{mol} \mathrm{U}$ ). All other parameters were kept constant in these tests. The results of these experiments are presented in Fig. 1. The obtained results indicated that the uranium stripping increases as the $\mathrm{H}_{2} \mathrm{O}_{2}$ content in the solution increases. A large excess of hydrogen peroxide is required for almost complete uranium stripping; therefore, the use of pure $\mathrm{H}_{2} \mathrm{O}_{2}$ solution for stripping is economically unviable.

The separation time of phases was also observed to decrease as the amount of excess $\mathrm{H}_{2} \mathrm{O}_{2}$ was increased due to an increase in the particle size of uranium peroxide.

\subsection{Effect of $\mathrm{NH}_{3}$ concentration on the uranium stripping}

The final $\mathrm{pH}$ of the aqueous phase was $0.16-0.28$ after stripping of uranium from TBP by using $\mathrm{H}_{2} \mathrm{O}_{2}$. Uranium peroxide is known to precipitate from solutions in a $\mathrm{pH}$ range of 2.5-4.0 (Cahill and Burkhart, 1990; Gupta et al., 2004; Morais et al., 2005; Morss et al., 2010; Watt et al., 1950). Therefore, diluted ammonia (5\%) was added to the stripping solution to maintain the desired $\mathrm{pH}$ for uranium peroxide precipitation. The experiments were performed using a stripping solution that contained 1-4 mol $\mathrm{H}_{2} \mathrm{O}_{2} / \mathrm{mol} \mathrm{U}$ and $0-15 \mathrm{~g} / \mathrm{L} \mathrm{NH}_{3}$. The phase contact time was $0.15 \mathrm{~h}$ after stirring was stopped. The final $\mathrm{pH}$ of the aqueous phase was recorded after the phases separated. The results are shown in Fig. 2. The extent of uranium stripping was found to increase as the final $\mathrm{pH}$ of aqueous phase increased. The ammonia concentration in the stripping solution should be $12-15 \mathrm{~g} / \mathrm{L}$ (i.e., the final $\mathrm{pH}$ of the aqueous phase should be in the range 2.73.3) to achieve efficient uranium peroxide precipitation (98\%). Some part of the uranium was observed to precipitate as ammonium uranate at $\mathrm{NH}_{3}$ concentrations greater than $15 \mathrm{~g} / \mathrm{L}$ (i.e., when the final $\mathrm{pH}$ of the aqueous phase was greater than 3.3).

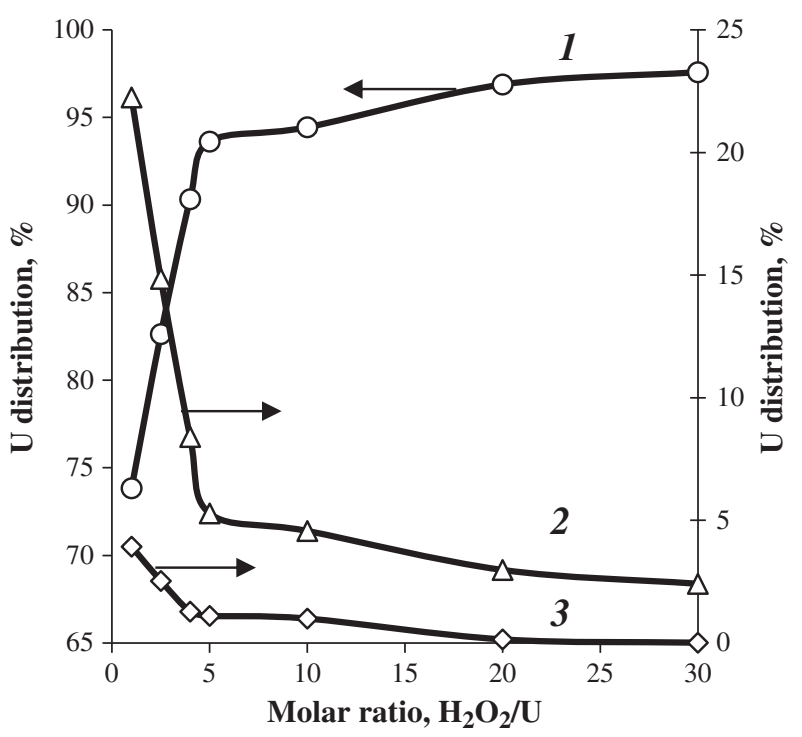

Fig. 1. The effect of $\mathrm{H}_{2} \mathrm{O}_{2}$ content in solution on uranium distribution during stripping from loaded organic phase: 1 - uranium peroxide; 2 - organic phase; 3 - aqueous phase. 


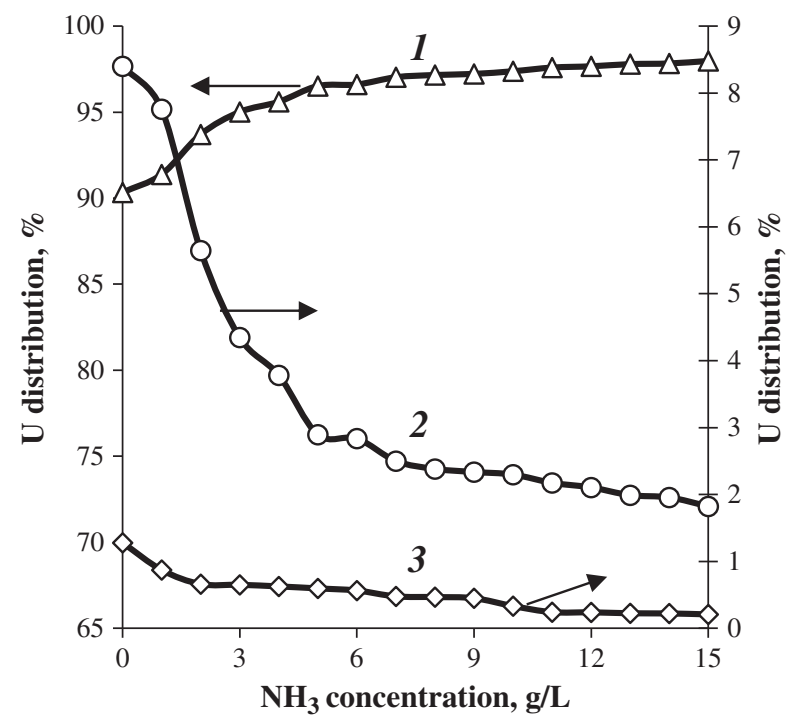

Fig. 2. The effect of $\mathrm{NH}_{3}$ concentration on uranium distribution during stripping from loaded organic phase by solution containing $4 \mathrm{~mol} \mathrm{H}_{2} \mathrm{O}_{2} / \mathrm{mol} \mathrm{U}$ : 1 - uranium peroxide; 2 - organic phase; 3 - aqueous phase.

\subsection{Effect of temperature on the uranium stripping}

Uranium was stripped from the loaded organic phase at different temperatures $\left(20-50{ }^{\circ} \mathrm{C}\right)$ with the other parameters held constant. Tests were performed using a solution that contained $4 \mathrm{~mol} \mathrm{H}_{2} \mathrm{O}_{2} / \mathrm{mol}$ $\mathrm{U}$ and $12 \mathrm{~g} / \mathrm{L} \mathrm{NH}_{3}$. The phase contact time was $0.15 \mathrm{~h}$ after stirring was stopped. The results are shown in Fig. 3. The uranium stripping was found to increase as the temperature was increased in the range of 20 to $40{ }^{\circ} \mathrm{C}$ and to decrease at temperatures greater than $40{ }^{\circ} \mathrm{C}$. The decrease at temperatures greater than $40{ }^{\circ} \mathrm{C}$ occurred because the hydrogen peroxide decomposed more rapidly at these temperatures. Thus, when the temperature is increased, additional $\mathrm{H}_{2} \mathrm{O}_{2}$ is required for uranium stripping. The amount of uranium stripped from the loaded organic phase was maximal at a temperature of $40{ }^{\circ} \mathrm{C}$. In this case, $98.8 \%$ of uranium was stripped in the form of uranium peroxide precipitate.

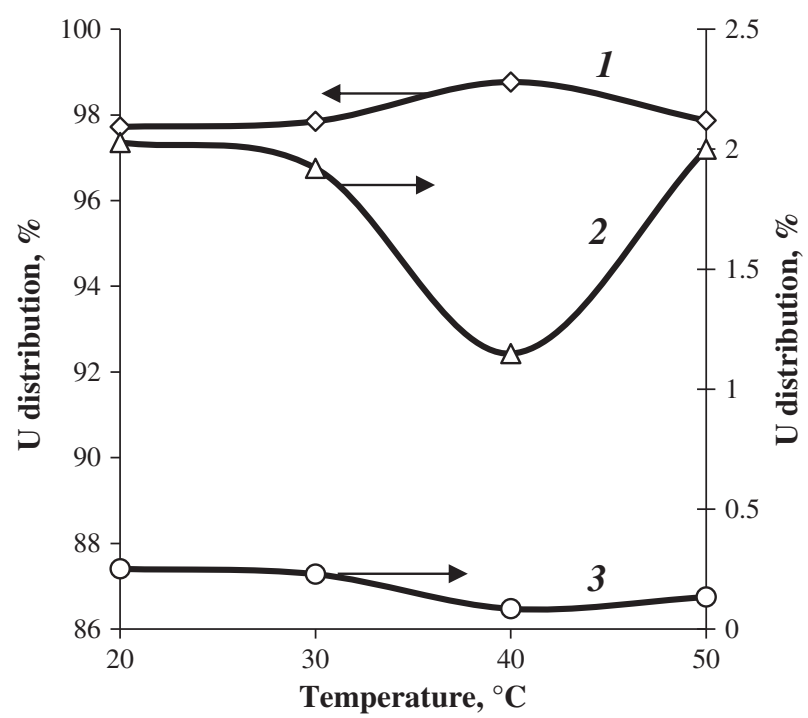

Fig. 3. The effect of temperature on uranium distribution during stripping from loaded organic phase by solution containing $4 \mathrm{~mol} \mathrm{H}_{2} \mathrm{O}_{2} / \mathrm{mol} \mathrm{U}$ and $12 \mathrm{~g} / \mathrm{L} \mathrm{NH}_{3}: 1$ - uranium peroxide; 2 - organic phase; 3 - aqueous phase.

\subsection{Effect of holding time on uranium stripping}

The effect of the phase contact time after stirring (i.e., the holding time) on uranium stripping was studied using $0.2 \mathrm{~L}$ of the loaded organic phase. The stripping studies were performed in a separatory funnel $(500 \mathrm{~mL})$ at temperatures from 20 to $40{ }^{\circ} \mathrm{C}$ using $\mathrm{H}_{2} \mathrm{O}_{2}$ solutions (1-4 mol $\mathrm{H}_{2} \mathrm{O}_{2} / \mathrm{mol} \mathrm{U}$ ) both with and without $\mathrm{NH}_{4} \mathrm{OH}$ added (12 $\mathrm{g} / \mathrm{L} \mathrm{NH}_{3}$ ). Samples of the organic and aqueous phases were drawn hourly, and their uranium content was analyzed. The results indicate that the amount of uranium stripped from the loaded organic phase increases as the holding time is increased. The uranium stripping was almost complete within 10-24 h (Fig. 4). However, 99.7\% of the uranium was precipitated from the organic phase after a holding time of $3 \mathrm{~h}$ at a temperature of $40{ }^{\circ} \mathrm{C}$ when the stripping solution contained $4 \mathrm{~mol} \mathrm{H} \mathrm{H}_{2} / \mathrm{mol} \mathrm{U}$ and $12 \mathrm{~g} / \mathrm{L} \mathrm{NH}_{3}$. The final $\mathrm{pH}$ of the aqueous phase was 3.3. For all subsequent studies, these parameters were accepted as the optimal conditions for uranium stripping.

\subsection{Effect of hydrogen peroxide on the organic phase}

TBP is known to be sufficiently chemically and radiation stable (Barelko et al., 1966). TBP is well able to withstand physical destruction and chemical oxidation. However, under certain conditions, TBP is decomposed to dibutyl phosphate (DBP) and monobutyl phosphate (MBP), which form stronger complexes with certain impurity metal ions and promote their extraction from an aqueous solution into an organic phase (Barelko et al., 1966; Pai et al., 1982). Hydrogen peroxide is a strong oxidant. Therefore, the effect of $\mathrm{H}_{2} \mathrm{O}_{2}$ on TBP was studied by IR spectroscopy. Fig. 5 shows the spectrum of 30\% TBP in odorless kerosene before extraction (curve 1) and after uranium was stripped under the optimal conditions previously described (curve 2). The IR spectrum shows the following major regions: a weak broad band in the $400-550 \mathrm{~cm}^{-1}$ region due to the deformation of $\mathrm{P}=\mathrm{O}$; an asymmetric and a symmetric bending of the ONO group at 669 and $722 \mathrm{~cm}^{-1}$, respectively; weak bands at 735 and $771 \mathrm{~cm}^{-1}$, which are assigned to $\mathrm{CH}_{2}$ groups; small bands at 867 and $959 \mathrm{~cm}^{-1}$, which are assigned to the symmetric and asymmetric stretching vibrations of the uranyl group, respectively; a C-C stretching vibration band at $911 \mathrm{~cm}^{-1}$; stretching vibrations of the $\mathrm{P}-\mathrm{O}-(\mathrm{C})$ group at 992,1029 and $1061 \mathrm{~cm}^{-1}$; bands at 1120 and $1151 \mathrm{~cm}^{-1}$, which are assigned to the stretching vibrations of the $\mathrm{C}-\mathrm{O}-(\mathrm{P})$ group; stretching

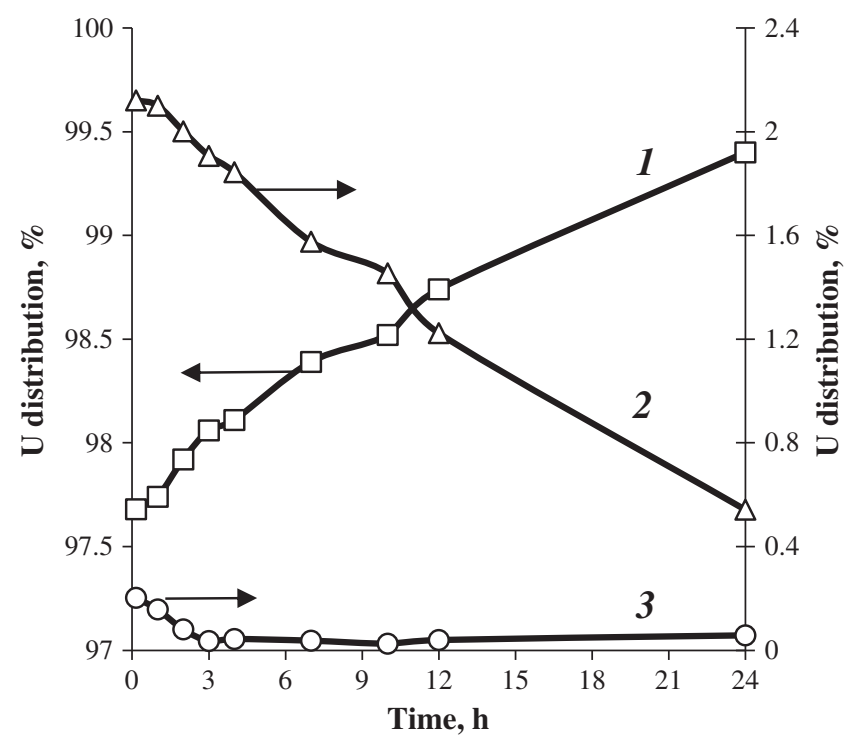

Fig. 4. The effect of holding time on uranium distribution during stripping from loaded organic phase by solution containing $4 \mathrm{~mol} \mathrm{H}_{2} \mathrm{O}_{2} / \mathrm{mol} \mathrm{U}$ and $12 \mathrm{~g} / \mathrm{L} \mathrm{NH}_{3}: 1$ - uranium peroxide; 2 - organic phase; 3 - aqueous phase. 


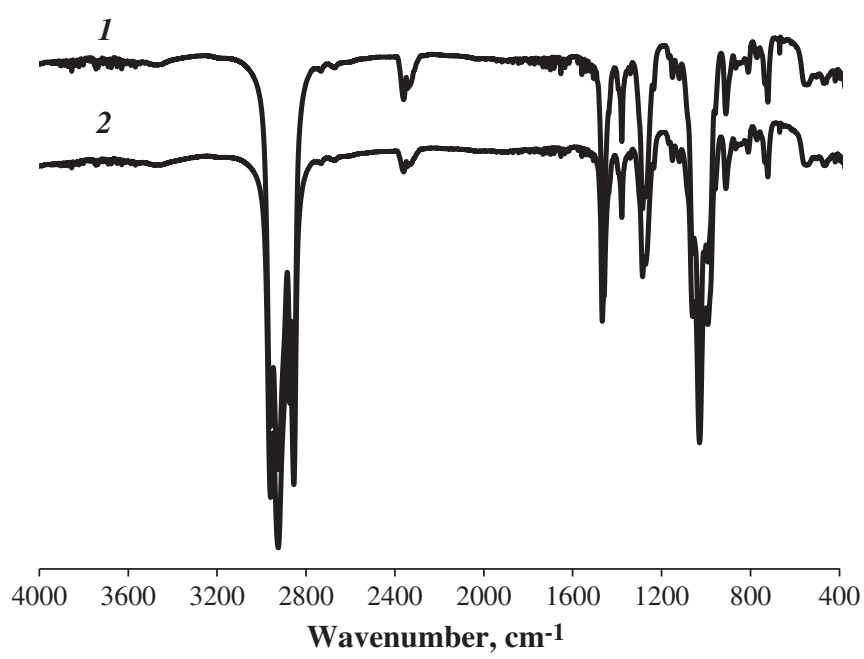

Fig. 5. Infrared spectra for organic phase: 1 - before uranium extraction; 2 - after uranium stripping by hydrogen peroxide solution.

vibrations of the $\mathrm{P}=\mathrm{O}$ group at 1236,1272 and $1285 \mathrm{~cm}^{-1}$; bands in $1350-1500 \mathrm{~cm}^{-1}$ region, which are characterized by the bending vibrations of $\mathrm{CH}_{3}$ and $\mathrm{CH}_{2}$ groups; and bands in the $2800-3000 \mathrm{~cm}^{-1}$ region due to the symmetric and asymmetric stretching vibrations of $\mathrm{CH}_{3}, \mathrm{CH}_{2}$ and $\mathrm{CH}$ groups. The IR bands assignments are consistent with those in the literature (Bagnall and Wakerley, 1975; Borkowski et al., 2002; Ohwada, 1968; Piras, 2002; Sato, 1965). The peak in $2250-2550 \mathrm{~cm}^{-1}$ region is assigned to uncompensated interference due to carbon dioxide in the atmosphere of the sample compartment Fig. 5 and Fig. 9). According to the results of the investigations, structural changes in the organic phase were not observed after 30 cycles of extraction/stripping. The bands of MBP, DBP and other third phases were not observed in the spectra. Thus, hydrogen peroxide can be used for uranium stripping without restriction.

\subsection{Properties of uranium peroxide}

In all the experiments, the uranium peroxide precipitates were filtered, washed and dried in air at room temperature $\left(20-25^{\circ} \mathrm{C}\right)$. The precipitated uranium peroxide was studied using various methods. Figs. 6-9 and Table 1 show the results of the characterization of the

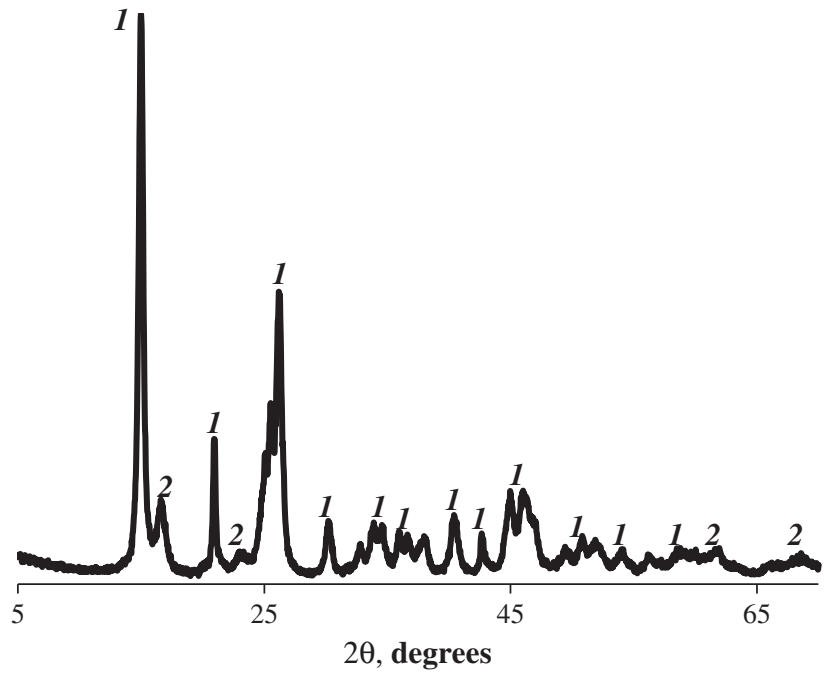

Fig. 6. X-ray powder diffraction pattern of uranium peroxide: $1-\mathrm{UO}_{4} \cdot 4 \mathrm{H}_{2} \mathrm{O} ; 2$ $\mathrm{UO}_{4} \cdot 2 \mathrm{H}_{2} \mathrm{O}$.

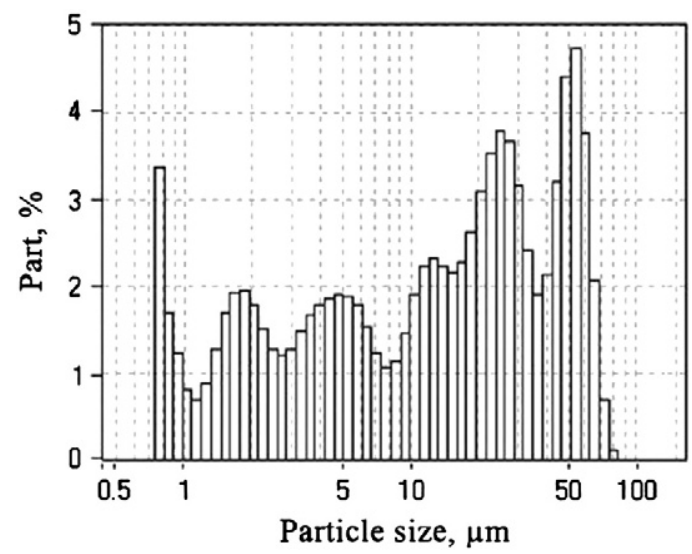

Fig. 7. Particle size distribution of uranium peroxide.

uranium peroxide that was precipitated from the loaded organic phase under the previously described optimized conditions.

As a result, uranium peroxide exists in two different hydrated forms: $\mathrm{UO}_{4} \cdot 4 \mathrm{H}_{2} \mathrm{O}$ and $\mathrm{UO}_{4} \cdot 2 \mathrm{H}_{2} \mathrm{O}$ (Fig. 6). According to the results of the analyses, the basic phase of uranium peroxide hydrate is the tetrahydrate phase (approximately 92 mass\%). This result is in agreement with the results of previous studies of uranium peroxide precipitation from aqueous solutions of uranyl nitrate with hydrogen peroxide (Sato, 1961; Sato, 1963). The particle size distribution of the product is shown in Fig. 7. The particle mean diameter is $20.75 \mu \mathrm{m}$. The results of the chemical analyses of the uranium peroxide are given in Table 1. Analysis of the data leads to the conclusion that the uranium peroxide obtained by stripping is a high-purity product. The $\mathrm{U}_{3} \mathrm{O}_{8}$ content in the product is $90.14 \%$.

The thermal decomposition of the uranium peroxide precipitate was investigated by TGA, DTA and infrared spectroscopy. The TGA and DTA curves are shown in Fig. 8. The DTA curve shows three endothermic peaks: the decomposition of $\mathrm{UO}_{4} \cdot 4 \mathrm{H}_{2} \mathrm{O}$ to $\mathrm{UO}_{4} \cdot 2 \mathrm{H}_{2} \mathrm{O}$ at approximately $130{ }^{\circ} \mathrm{C}$, the decomposition of $\mathrm{UO}_{4} \cdot 2 \mathrm{H}_{2} \mathrm{O}$ to hydrated $\mathrm{UO}_{3}$ at approximately $245{ }^{\circ} \mathrm{C}$ and the conversion of $\mathrm{UO}_{3}$ to $\mathrm{U}_{3} \mathrm{O}_{8}$ at approximately $628{ }^{\circ} \mathrm{C}$. These reactions occur at points near the change in shape of the TGA curve. In addition, the TGA curve shows a small loss in weight at approximately $383^{\circ} \mathrm{C}$. This weight loss is due to the dehydration of hydrated $\mathrm{UO}_{3}$. The TGA/DTA data is in good agreement with the infrared spectroscopy results. Infrared spectra of the uranium peroxide and the thermal decomposition products are shown in Fig. 9. The infrared spectrum of uranium peroxide powder, which was recorded at room temperature $\left(22^{\circ} \mathrm{C}\right)$, is shown in Fig. 9 (1). This spectrum contains several absorption bands with maxima at $3500,3152,1624,1384,907,728$ and $469 \mathrm{~cm}^{-1}$. The two broad bands with maxima at 3500 and $3152 \mathrm{~cm}^{-1}$ are due to the

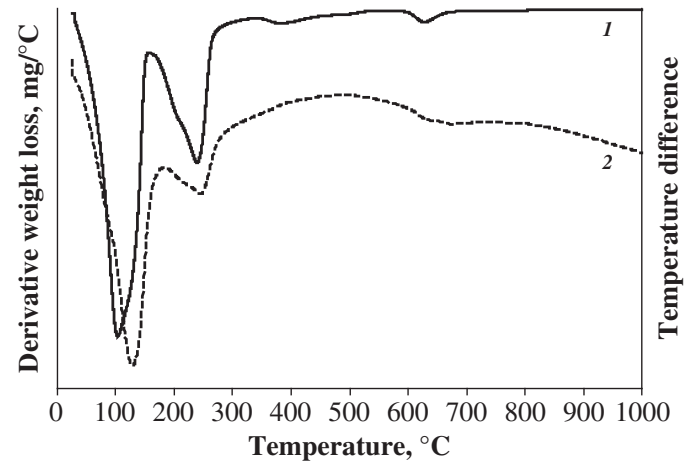

Fig. 8. TGA (1) and DTA (2) curves for uranium peroxide. 


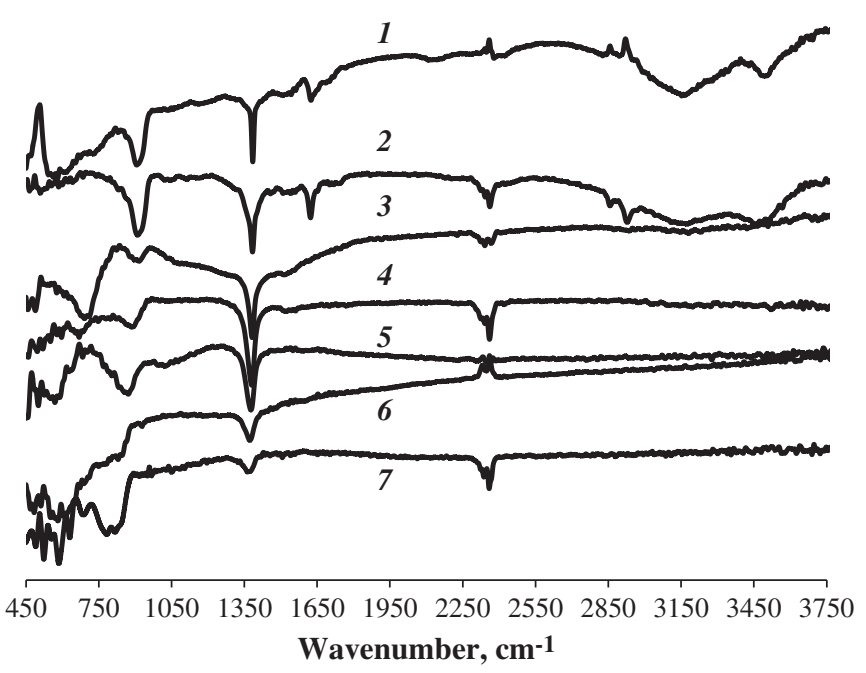

Fig. 9. Infrared spectra for uranium peroxide at different temperatures: $1-22{ }^{\circ} \mathrm{C} ; 2$ $100{ }^{\circ} \mathrm{C} ; 3-200{ }^{\circ} \mathrm{C} ; 4-300{ }^{\circ} \mathrm{C} ; 5-400{ }^{\circ} \mathrm{C} ; 6-500{ }^{\circ} \mathrm{C} ; 7-600{ }^{\circ} \mathrm{C}$.

$\mathrm{O}-\mathrm{H}$ stretching vibrations. The sharp peak at $1624 \mathrm{~cm}^{-1}$ is attributed to the vibrational bending mode of $\mathrm{H}_{2} \mathrm{O}$. The absorption band at $907 \mathrm{~cm}^{-1}$ is due to the asymmetric vibrations of the uranyl group. The band at $728 \mathrm{~cm}^{-1}$ is attributed to the vibration of $\mathrm{H}_{2} \mathrm{O}$ groups. The highly intense band at $1384 \mathrm{~cm}^{-1}$ is due to the symmetric deformation of $\mathrm{NH}_{3}$; this band is probably due to the presence of a $\mathrm{NH}_{4}^{+}$impurity. The band at approximately $469 \mathrm{~cm}^{-1}$ is assigned to $\mathrm{U}-\mathrm{O}$ stretching. IR spectra of uranium peroxide heated at increasing temperatures in the range of 100 to $600{ }^{\circ} \mathrm{C}$ are shown in Fig. $9(2-7)$. In the $22-200{ }^{\circ} \mathrm{C}$ range, new bands at $400-800 \mathrm{~cm}^{-1}$ appeared in the spectrum due to the decomposition of $\mathrm{UO}_{4} \cdot 4 \mathrm{H}_{2} \mathrm{O}$ to $\mathrm{UO}_{4} \cdot 2 \mathrm{H}_{2} \mathrm{O}$. At $100{ }^{\circ} \mathrm{C}$, the $\mathrm{OH}$-stretching band at $3152 \mathrm{~cm}^{-1}$ split into two bands at 2927 and $3158 \mathrm{~cm}^{-1}$. Between 200 and $300{ }^{\circ} \mathrm{C}$, the $\mathrm{OH}$-group bands disappeared completely, whereas new bands appeared at 681 and $892 \mathrm{~cm}^{-1}$ due to the U-O stretching vibration of $\mathrm{UO}_{3}$. The intensity and position of these bands changed at $300-500{ }^{\circ} \mathrm{C}$. In the $500-600{ }^{\circ} \mathrm{C}$ range, the intensity of the band at $1384 \mathrm{~cm}^{-1}$ decreased. At $600{ }^{\circ} \mathrm{C}$, a strong band appeared at $800 \mathrm{~cm}^{-1}$ due to the asymmetric stretching frequency of the uranyl group of $\mathrm{U}_{3} \mathrm{O}_{8}$. These TGA/DTA and IR spectroscopy results are consistent with the results of previous research reported in the literature (Cordfunke and Aling, 1963; Deane, 1961; Hoekstra and Siegel, 1961; Sato, 1976; Singh et al., 2004; Varga et al., 2011).

All of the results of the studies of the other precipitates obtained under different conditions were similar to those previously described, although they are not presented in this paper.

\section{Conclusions}

The results of this work clearly indicate that uranium can be effectively stripped from a loaded organic phase using hydrogen peroxide. The use of a hydrogen peroxide solution for stripping results in the precipitation of uranium in the form of uranium peroxide, and $99.7 \%$ of the uranium was precipitated as uranium peroxide from a loaded organic phase that contained $78 \mathrm{~g} / \mathrm{L} \mathrm{U}(\mathrm{VI})$ and $15.34 \mathrm{~g} / \mathrm{L}$

Table 1

Impurity elements in uranium peroxide $\left(\times 10^{-3} \%\right)$, nf: not found.

\begin{tabular}{llllll}
\hline $\mathrm{Fe}$ & 4.1 & $\mathrm{Mo}$ & 0.09 & $\mathrm{Al}$ & $\mathrm{nf}$ \\
$\mathrm{K}$ & 0.9 & $\mathrm{~V}$ & $\mathrm{nf}$ & $\mathrm{Cu}$ & $\mathrm{nf}$ \\
$\mathrm{Na}$ & 4.0 & $\mathrm{Si}$ & $\mathrm{nf}$ & $\mathrm{Pb}$ & $\mathrm{nf}$ \\
$\mathrm{S}$ & 15.8 & $\mathrm{P}$ & 3.7 & $\mathrm{Ni}$ & $\mathrm{nf}$ \\
$\mathrm{Ca}$ & $\mathrm{nf}$ & $\mathrm{B}$ & 0.02 & $\mathrm{Mn}$ & 0.6 \\
$\mathrm{Cr}$ & $\mathrm{nf}$ & $\mathrm{Cl}$ & $\mathrm{nf}$ & $\mathrm{Li}$ & $\mathrm{nf}$ \\
$\mathrm{W}$ & 0.01 & $\mathrm{Ti}$ & $\mathrm{nf}$ & $\mathrm{Mg}$ & $\mathrm{nf}$ \\
\hline
\end{tabular}

$\mathrm{HNO}_{3}$ under the following conditions: $\mathrm{O} / \mathrm{A}=1$; stripping solution $\mathrm{H}_{2} \mathrm{O}_{2}$ content $4 \mathrm{~mol} / \mathrm{mol} \mathrm{U}, \mathrm{NH}_{3}$ content $12 \mathrm{~g} / \mathrm{L}$; holding time $3 \mathrm{~h}$; final $\mathrm{pH}$ of aqueous phase 3.3 ; stripping temperature $40{ }^{\circ} \mathrm{C}$. The uranium peroxide obtained under these conditions is a highly pure product with a mean particle diameter of $20.75 \mu \mathrm{m}$. The $\mathrm{U}_{3} \mathrm{O}_{8}$ content in the product is $90.14 \%$. We found that the basic phase of uranium peroxide is $\mathrm{UO}_{4} \cdot 4 \mathrm{H}_{2} \mathrm{O}$. The hydrogen peroxide was found to not affect the organic phase; thus $\mathrm{H}_{2} \mathrm{O}_{2}$ can be used unrestricted.

The uranium peroxide obtained in this work was converted to $\mathrm{UF}_{4}$. According to previous studies, this $\mathrm{UF}_{4}$ can be used to produce $\mathrm{UF}_{6}$ that corresponds to ASTM C787-11.

\section{References}

Bagnall, K.W., Wakerley, M.W., 1975. Infrared and Raman spectra of the uranyl ion. J. Inorg. Nucl. Chem. 37 (1), 329-330.

Barelko, E.P., Solyanina, I.P., Tsvetkova, Z.I., 1966. Radiation-chemical stability of TBP in solutions of hydrocarbons. At. Energy 21 (4), 946-950.

Borkowski, M., Ferraro, J.R., Chiarizia, R., McAlister, D.R., 2002. FT-IR study of third phase formation in the $\mathrm{U}(\mathrm{VI})$ or $\mathrm{Th}(\mathrm{IV}) / \mathrm{HNO}_{3} \mathrm{TBP} /$ alkane system. Solvent Extr. Ion Exch. 20 (3), 313-330.

Cahill, A.E., Burkhart, L.E., 1990. Continuous precipitation of uranium with hydrogen peroxide. Metall. Mater. Trans. B 21 (5), 819-826.

Caropreso, F.E., Kreuz, D.F., 1977. Production of uranium peroxide, US Patent, US4024215 (C01G 43/00).

Cordfunke, E.H.P., Aling, P., 1963. Thermal decomposition of hydrated uranium peroxides. Recl. Trav. Chim. Pays-Bas 82 (3), 257-263.

Deane, A.M., 1961. The infra-red spectra and structures of some hydrated uranium trioxides and ammonium diuranates. J. Inorg. Nucl. Chem. 21 (3-4), 238-252.

Edwards, C., Oliver, A., 2000. Uranium processing: a review of current methods and technology. JOM 52 (9), 12-20.

Gupta, R., Pandey, V.M., Pranesh, S.R., Chakravarty, A.B., 2004. Study of an improved technique for precipitation of uranium from eluted solution. Hydrometallurgy 71 (3-4), 429-434.

Hardwick, T.J., 1984. Method of precipitating uranium peroxide, US Patent, US4428911 (C01G 43/01; C22B 60/02).

Hausen, D., 1998. Characterizing and classifying uranium yellow cakes: a background. JOM 50 (12), 45-47.

Hoekstra, H.R., Siegel, S., 1961. The uranium-oxygen system: $\mathrm{U}_{3} \mathrm{O}_{8}-\mathrm{UO}_{3}$. J. Inorg. Nucl. Chem. 18, 154-165.

Kim, K.-W., et al., 2011. Effects of the different conditions of uranyl and hydrogen peroxide solutions on the behavior of the uranium peroxide precipitation. J. Hazard. Mater. 193, 52-58.

Morais, C.A., Gomiero, L.A., Filho, W.S., Rangel Jr., H., 2005. Uranium stripping from tertiary amine by sulfuric acid solution and its precipitation as uranium peroxide. Miner. Eng. 18 (13-14), 1331-1333.

Morss, L.R., Edelstein, N.M., Fuger, J., 2010. The Chemistry of the Actinide and Transactinide Elements, 1-6. Springer, Netherlands.

Ohwada, K., 1968. Infrared spectra of organic phosphates in the combination region of the $\mathrm{C}-\mathrm{O}$ and $\mathrm{P}-\mathrm{O}$ vibrations. Appl. Spectrosc. 22, 209.

Pai, S., Shukla, J., Subramanian, M., 1982. Extraction behaviour of uranium, zirconium and ruthenium with gamma-irradiated sulfoxides and tri-n-butyl phosphate. J. Radioanal. Nucl. Chem. 74 (1), 31-38.

Piras, F.M., 2002. In situ attenuated total reflection tribometry: a new approach for the chemical analysis of tribological films. (PhD Thesis) ETH Zurich, Zurich (106-109 pp.).

Sato, T., 1958. The extraction of uranyl nitrate from nitric acid solutions by tributyl phosphate. J. Inorg. Nucl. Chem. 6 (4), 334-337.

Sato, T., 1961. Uranium peroxide hydrates. Naturwissenschaften 48 (21), 668.

Sato, T., 1963. Preparation of uranium peroxide hydrates. J. Appl. Chem. 13 (8), 361-365.

Sato, T., 1965. Extraction of uranium (VI) and thorium from nitric acid solutions by trin-butyl phosphate. J. Appl. Chem. 15 (11), 489-495.

Sato, T., 1976. Thermal decomposition of uranium peroxide hydrates. J. Appl. Chem. Biotech. 26 (1), 207-213.

Shabbir, M., Tame, K.E., 1974. Hydrogen peroxide precipitation of uranium. Report of investigations, RI 7931.U.S. Bureau of Mines, Washington.

Singh, D.K., Mishra, S.L., Singh, H., 2002. Recovery of uranium as uranium peroxide from acidic solution using hydrogen peroxide. Proc. Int. Conf. Solv. Extr. ISSE, Bhubaneshwar, India. 399-404.

Singh, H., Mishra, S.L., Vijayalakshmi, R., 2004. Uranium recovery from phosphoric acid by solvent extraction using a synergistic mixture of di-nonyl phenyl phosphoric acid and tri-n-butyl phosphate. Hydrometallurgy 73 (1-2), 63-70.

Varga, Z., et al., 2011. Characterization and classification of uranium ore concentrates (yellow cakes) using infrared spectrometry. Radiochim. Acta 99 (12), 807-813.

Watt, G.W., Achorn, S.L., Marley, J.L., 1950. Some chemical and physical properties of uranium peroxide. J. Am. Chem. Soc. 72 (8), 3341-3343.

Wilson, P.D., 1996. The Nuclear Fuel Cycle: from Ore to Wastes. Oxford University Press, Oxford. 